\title{
Detection and assessment of electrocution in endangered raptors by infrared thermography
}

\author{
Mar Melero ${ }^{1 *}$, Fernando González², Olga Nicolás ${ }^{3}$, Irene López ${ }^{2}$, María de los Ángeles Jiménez ${ }^{4}$ \\ Susana Jato-Sánchez ${ }^{2}$ and José Manuel Sánchez-Vizcaíno ${ }^{1}$
}

\begin{abstract}
Background: Most European birds of prey find themselves in a poor state of conservation, with electrocution as one of the most frequent causes of unnatural death. Since early detection of electrocution is difficult, treatment is usually implemented late, which reduces its effectiveness. By considering that electrocution reduces tissue temperature, it may be detectable by thermography, which would allow a more rapid identification. Three individuals from three endangered raptor species [Spanish imperial eagle (Aquila adalberti), Lammergeier (Gypaetus barbatus) and Osprey (Pandion haliaetus)] were studied thermographically from the time they were admitted to a rehabilitation centre to the time their clinical cases were resolved.

Cases presentation: The three raptors presented lesions lacking thermal bilateral symmetry and were consistent with electrocution of feet, wings and eyes, visible by thermography before than clinically; lesions were well-defined and showed a lower temperature than the surrounding tissue. Some lesions evolved thermally and clinically until the appearance of normal tissue recovered, while others evolved and became necrotic. A histopathological analysis of a damaged finger amputated off a Lammergeier, and the necropsy and histopathology examination of an osprey, confirmed the electrocution diagnosis.
\end{abstract}

Conclusions: These results suggest that thermography is effective and useful for the objective and early detection and monitoring of electrocuted birds, and that it may prove especially useful for examining live animals that require no amputation or cannot be subjected to invasive histopathology.

Keywords: Thermography, Electrocution, Raptor, Bird of prey, Spanish imperial eagle, Lammergeier, Osprey

\section{Background}

Birds of prey have been proposed as good sentinels of environmental changes as they are placed at the top of the food chain and are widespread worldwide [1]. However, $36(64 \%)$ of the 56 species of raptors inhabiting Europe find themselves in an unfavourable state of conservation [2]. Most raptor deaths are caused by direct and indirect actions of humans [1]. One of the most common causes of unnatural death is electrocution as a result of collisions with power lines and the subsequent trauma when the animal falls to the ground [1,3,4]. While unnatural mortality can be compensated in a healthy population, it can seriously affect a small population [5]. For example, electrocution poses a significant

\footnotetext{
* Correspondence: mar.melero@sanidadanimal.info

'VISAVET Centre and Animal Health Department, Veterinary School,

Complutense University of Madrid, 28040 Madrid, Spain

Full list of author information is available at the end of the article
}

survival problem for one of the most endangered raptors in the world, the Spanish imperial eagle [6].

The accuracy of electrocution mortality estimates is limited given the difficulty in determining cause of death [7]. Since determination of electrocution is usually based on anamnesis and clinical signs, i.e., electrical burns [1], detecting and evaluating an electrocuted bird can prove most difficult since anamnesis is often incomplete, and evidence for electrical trauma may not be immediately detectable [8]. Moreover, an early diagnosis of electrocution is essential for a good prognosis. For these reasons, complementary diagnostic tools, such as histopathology, are used when an amputation or necropsy is required $[1,9]$. Nevertheless, histopathology is invasive and may not be feasible or advisable for live animals, especially those that do not require amputation.

Thermography is a non-invasive technique used to assess tissue temperature that can be applied to electrocution 
detection and assessment. It can be used at a distance of more than $500 \mathrm{~m}$ from the animal [10], reducing its stress and ensuring the safety of the technician. Physiological and pathological thermographic patterns have not yet been established for most species. Nevertheless, reports of thermographic analyses have so far established that the thermal pattern and symmetry of the body are more important than the absolute temperature for diagnosing disease [11].

Tissue affected by electrocution shock shows reduced vascularisation, innervation, water content [12] and oxygen saturation [13]. These changes should result in a lower temperature in the affected area, thus raising the possibility that electrocution shock can be detected by thermography. Accordingly, this report applies thermography to detect and assess electrocution to three endangered raptors $[14,15]$.

\section{Cases presentation}

\section{Case 1: Spanish imperial eagle (Aquila adalberti)}

On 11 September 2008, a juvenile female was admitted to the GREFA wildlife rehabilitation centre in Madrid (Spain). Clinical signs were 7\% dehydration, depression, emaciation, arrhythmias, bradycardia and a proximal closed right radial fracture. Electrical lesions were not observed initially, but became visible 3 days later. Treatment included rehydration, antibiotics, a figure-eight bandage on the right wing and physiotherapy on the right finger IV and the right wing. Finally, the animal was released on 16 March 2009.

For thermographic evaluation (Cases 1-3), a ThermaCAM E45 infrared thermocamera with an FOV25 lens was used and images were analysed using the ThermaCAM QuickReport 1.2 SP2 software (FLIR, Burlington, ON, Canada). In this case, the thermal examination upon admission revealed an abnormally low temperature in right finger IV as compared to the other fingers, and a markedly higher temperature area in the right wing, which was coincident with the radius fracture (Table 1, Figure 1(1,2)). During physiotherapy and rehabilitation, the thermal pattern of right finger IV and right wing became similar to that of the normal ones (Table 1, Figure 1(3)). Upon the first flight test, the eagle was unable to fly more than 5 seconds and deviated to the right and thermography of the right wing revealed an increase in the temperature of the muscles, especially in the elbow and carpus areas, probably due to the greater effort made by these less tone muscles in order to fly, as compared to the left wing, which presented the normal thermal pattern (Table 1, Figure 1(5)). For the remaining flight tests until the animal was released, the left and right wings showed the same thermal pattern.

After removing the bandage, the thermography of the wings revealed a significantly higher temperature in the right patagium area $\left(7.8^{\circ} \mathrm{C}\right)$ than in the left one $\left(4.4^{\circ} \mathrm{C}\right)$ with a similar maximum temperature in the middle of both ulna areas (Table 1, Figure 1(4)). This asymmetric thermal pattern was consistent with the patagium retraction caused by periods of immobilisation. Increased vascularity and inflammation in the patagium area led to an increased temperature, which was detected by thermography. Early detection of this pathology is essential for a good prognosis; otherwise, the disease can lead to the development of fibrous tissue, calcifications and tie downs [19], making impossible the animal releasing into the wild, the primary goal of rehabilitation of wildlife.

\section{Case 2: Lammergeier (Gypaetus barbatus)}

On 13 April 2012, an adult female was admitted to the fauna recuperation centre of Vallcalent, Lleida (Spain). The admission examination revealed proper body condition, good hydration and alert mental status. Nevertheless, the animal put little weight on the left limb and leaning instead on the dorsum of the foot. Treatment consisted of antibiotics, anti-inflammatory and physiotherapy on the left leg. The three most distal phalanges of left finger III were amputated 5 days after admission because their condition worsened despite treatment. The animal remained in the rehabilitation centre with a good prognosis, the amputated finger correctly healed and the left leg appeared strong and toned, and the animal was using it normally.

The first thermal examination showed an abnormal thermal pattern in left foot showing low temperatures and large temperature differences within finger III $\left(10.2^{\circ} \mathrm{C}\right)$ and less marked in finger IV $\left(8.4^{\circ} \mathrm{C}\right)$ compared with healthy ones $\left(<3.6^{\circ} \mathrm{C}\right)$, an unusually high temperature and an irregular thermal pattern in the left eye and a significantly high difference in temperature between the centres of the two corneas $\left(3.9^{\circ} \mathrm{C}\right)$ (Table 1 , Figure $2(1,2,7)$. But after six weeks of treatment, the thermal pattern of the left finger IV and the left eye were normal and the temperature varied only $3.7^{\circ} \mathrm{C}$ in finger IV and the intercorneal temperature difference $\left(0.7^{\circ} \mathrm{C}\right)$ was closer to that of eyes of healthy Lammergeiers $\left(<0.6^{\circ} \mathrm{C}\right)$ (Table 1 , Figure 2 $(3,8-11))$. Electrocution probably brought about the large intercorneal temperature difference and the loss of thermal structure in the left eye, and the deviations from bilateral symmetry decreased as the animal showed clinical improvement.

For the histology analysis (Cases 2, 3), tissue samples were fixed in formalin, lightly decalcified with nitrogen oxide when necessary, trimmed and paraffin-embedded. Tissues were then sectioned at a thickness of $4 \mu \mathrm{m}$ and stained with hematoxylin-eosin (H-E) for diagnosis purposes. After the amputation, the histopathological examination of left finger III revealed broad segments of full thickness dermal coagulative necrosis (Figure 2(4-6)). Keratinocytes had bright eosinophilic homogeneous 
Table 1 Thermal values at different anatomical areas

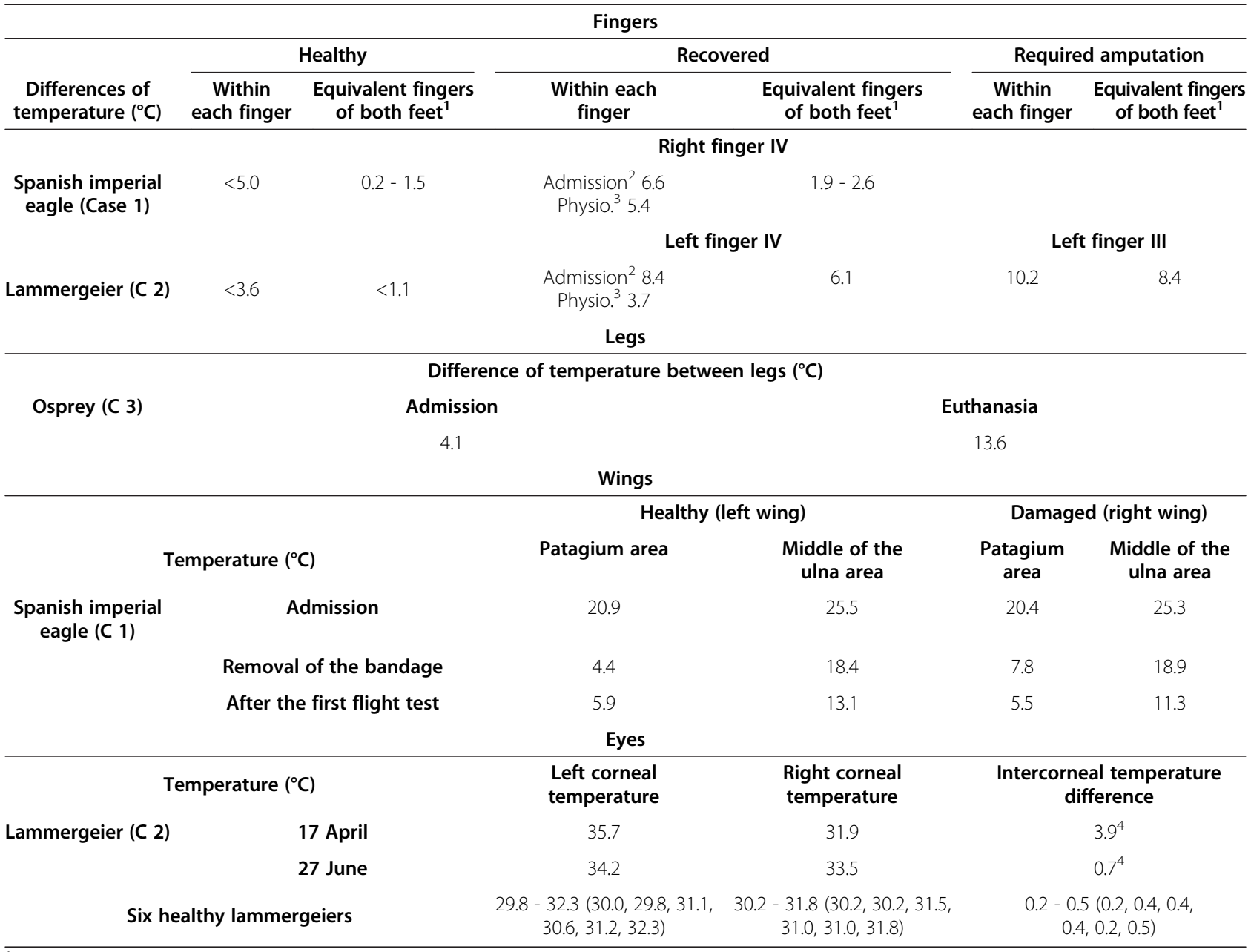

${ }^{1}$ Differences of minimum temperature of equivalent fingers of both feet measured at the same phalange.

${ }^{2}$ Thermal measurement upon admission.

${ }^{3}$ Thermal values after physiotherapy treatment.

${ }^{4}$ Difference above $0.6^{\circ} \mathrm{C}$, defined by Morgan et al. [16] as the upper limit for $95 \%$ of the normal population. Analysed by a randomisation test [17], the differences between damaged and healthy eyes are statistically significant $(p=0.036)$

Cases 1-3. Thermographic measurements of healthy and damaged fingers, legs, wings and eyes of the three clinical cases and the eyes of six healthy Lammergeiers.

cytoplasm, fused cell borders and streaming basophilic nuclei. Broad linear multifocal segments of deep dermis, panniculus and tendon sheaths had brightly eosinophilic, glassy and fragmented collagen fibres, separated by clear space, mucinous material and scattered clusters of heterophils, lymphocytes, plasma cells and macrophages. Some arterioles had mural aggregates of similar inflammatory cells and glassy walls. These findings of severe subacute cutaneous avascular necrosis and heterophilic dermatitis were consistent with a third-degree burn. The segmental pattern of the full thickness coagulative necrosis and the lack of external lesions until sometime after the animal was admitted into rehabilitation were suggestive of an electrical rather than heat burn [20]. Electric current flows through areas of least resistance; hence, tissue is differentially affected $[21,22]$.
Even before amputation, the thermography detected the abnormal thermal pattern and lack of thermal symmetry in left fingers III and IV, as well as the worse prognosis for finger III, thus supporting the idea that this non-invasive technique can gain useful clinical insights into affected animals.

\section{Case 3: Osprey (Pandion haliaetus)}

On 16 March 2012, a juvenile male was admitted to GREFA. The clinical examination revealed an open, comminuted fracture of the left radius and ulna. Treatment included antibiotics, anti-inflammatories and propentofylline. On 24 March 2012, an intramedullary needle was surgically implanted into the left radius and ulna. After surgery, the animal's condition continued to worsen; an oedema in the wing appeared and increased, and the animal could not stand up on its legs because of 


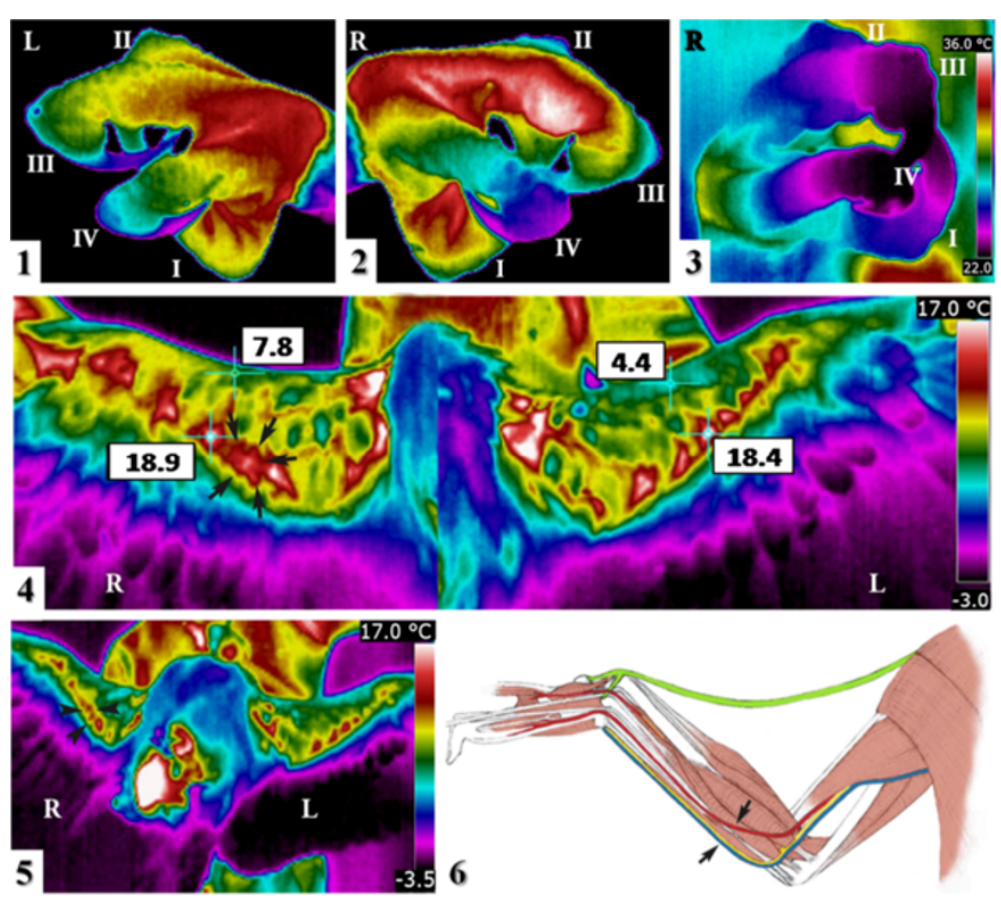

Figure 1 Thermal analysis of the Spanish imperial eagle (A. adalberti). Case 1. Thermography of feet; Lateral views of the (1) left foot and (2) the right foot upon admission, and (3) the right foot 35 days after admission. Roman numerals designate each finger (I-IV). A physiological thermal pattern is observed in the left foot and in right fingers I, II and III. The thermal range is the same for Figure 1(1-3). Thermography of wings; Ventral view of the wings taken (4) at the time the bandage was removed and (5) at the time of first flight test. A physiological thermal pattern is observed in the left wing. Initial designated right (R) and left ( $L$ ) legs and wings. (6) An anatomic diagram of the ventral view of a right wing, drawn based on a figure in Orosz et al. [18]. The tendon of the tensor propatagialis is shown in green. The area of the proximal right radial fracture is enclosed by arrows $(\mathbf{4}, \mathbf{6})$ and arrowheads $(\mathbf{5})$.

the neurovascular necrosis, which would have required amputation of the limb. Since amputation of the leg is incompatible with the hunting and feeding habits of this species, it was euthanised for humanitarian reasons on 28 March 2012 based on previous studies recommendations [23-25]. Then, necropsy was performed according to the protocol of Schmidt and Reavill [26,27].

Thermal examination upon admission revealed an abnormally high difference between legs, which deteriorated significantly from admission $\left(4.1^{\circ} \mathrm{C}\right)$ to the day that euthanasia was practiced $\left(13.6^{\circ} \mathrm{C}\right)$ (Table 1, Figure 3 ) and a high temperature area in the left wing, from the elbow to the carpus, coincident with the fracture and surrounding tissue; and a low temperature in the region distally from the carpus. The comminute fracture and consequent inflammation increased the temperature between the elbow and the carpus, while the effect of electrocution lowered the temperature between the carpus and the distal part of the wing. During treatment the thermal pattern in this region become more marked and sharper boundaries with the surrounding tissue as a result of the animal's worsened clinical status and of handling during surgery.
Necropsy revealed thinness, an oedema in the left wing, haematoma in ribs and keel, atrophied pectoral muscles, numerous clots distributed by all the vessels in lung and air sacs veins with yellowish deposits, thickened pericardium, myocardial greenish stain in the left ventricle, whitish injury in the apex, and liver yellowish and congestive encephalon. Cold oedemas mainly in the distal wing and coagulation in internal organs have been previously described as common necropsy findings in electrocuted birds [8]. The wing fracture and haematomas in pectoral muscles and keel were probably secondary to the fall after colliding with power lines.

The most remarkable histopathological findings were in the liver. The hepatic parenchyma had broad multifocal fragmented areas of coagulative necrosis surrounded by abundant immature granulation tissue and numerous foamy macrophages and giant multinucleated cells. The viable hepatic parenchyma adjacent to the granulation tissue was disorganized and contained numerous packed small groups of oval cells arranged in tubules (regeneration) and separated by moderate amounts of mature fibrous tissue, haemosiderin and bile-laden macrophages, heterophils and lymphocytes. The hepatic coagulative necrosis was suggestive of blunt trauma, often associated with electrocution 

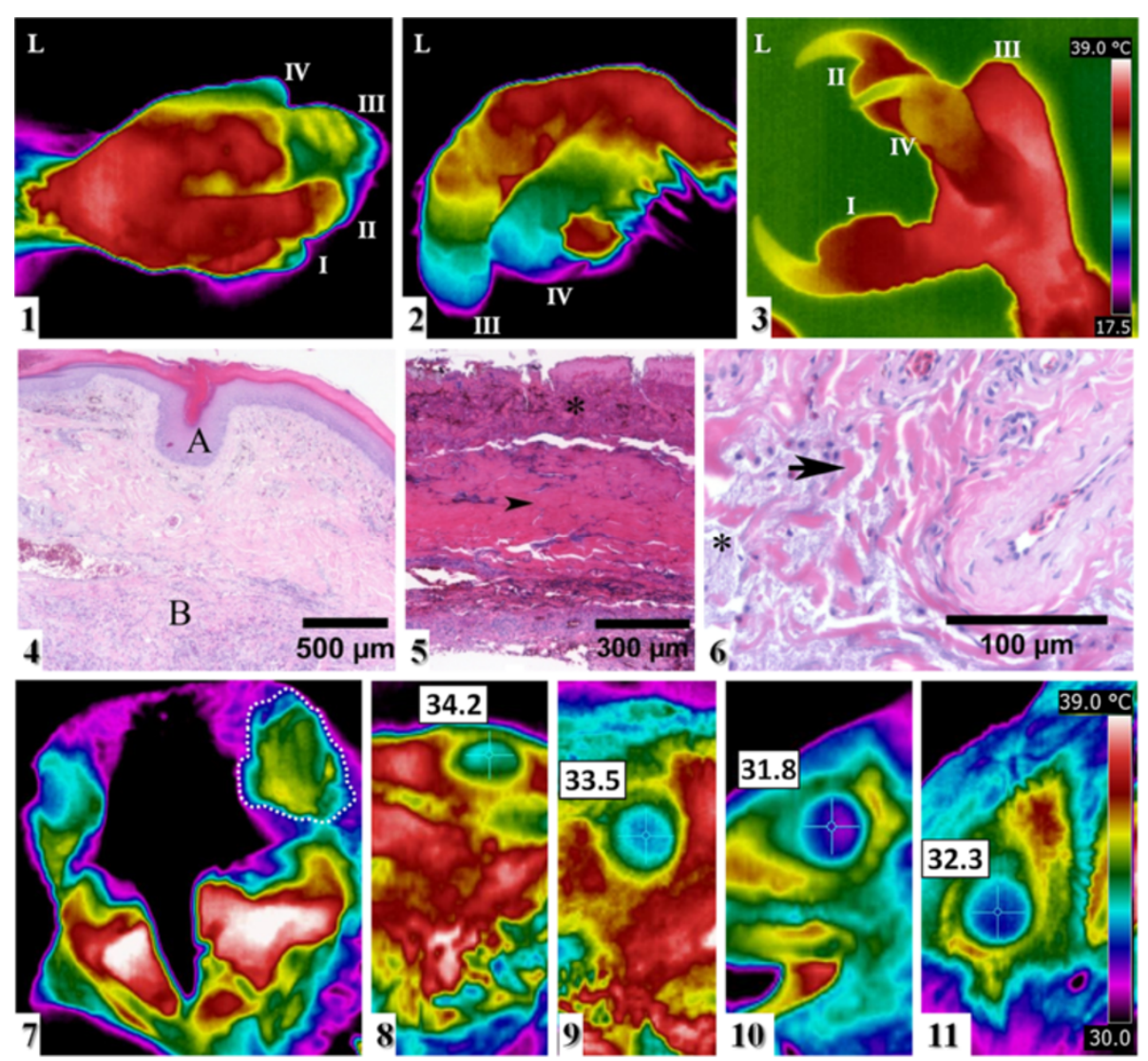

Figure 2 Thermal analysis of the Lammergeier (G. barbatus). Case 2. (1-3) Thermal images of the left foot, taken (1) of the dorsal view and (2) of the lateral view on 17 April and (3) of the lateral view on 27 June. Initial designated left (L) leg and roman numerals designate each finger (I-IV). A physiological thermal pattern is observed in fingers I and II. (4-6) A histology section of left digit III stained with haematoxylin and eosin showing: (4) epidermis within normal limits (A) and deep dermis with broad linear segments of mixed inflammatory cells, oedema fluid and fragmented collagen fibres (B); (5) full thickness segmental coagulative necrosis with crushed keratinocyte nuclei (asterisk) and dermal collagenolysis (arrow head); (6) detail of mucinous material (asterisk) and smudged collagen fibres (arrow). Thermal images of eyes of two Lammergeiers. (1-3) Clinical case 2 before and during treatment: (1) Frontal view of the head taken on 17 April. The left eye is enclosed by a dotted line. A physiological thermal pattern is observed in the right eye. Lateral view of (2) the left eye and (3) the right eye, both taken on 27 June. $(\mathbf{4}, \mathbf{5})$ Healthy Lammergeier, lateral view of $\mathbf{( 4 )}$ the left eye and $\mathbf{( 5 )}$ the right eye. The thermal range is the same for Figure $1(\mathbf{1 - 3})$ and for Figure 2(7-11).
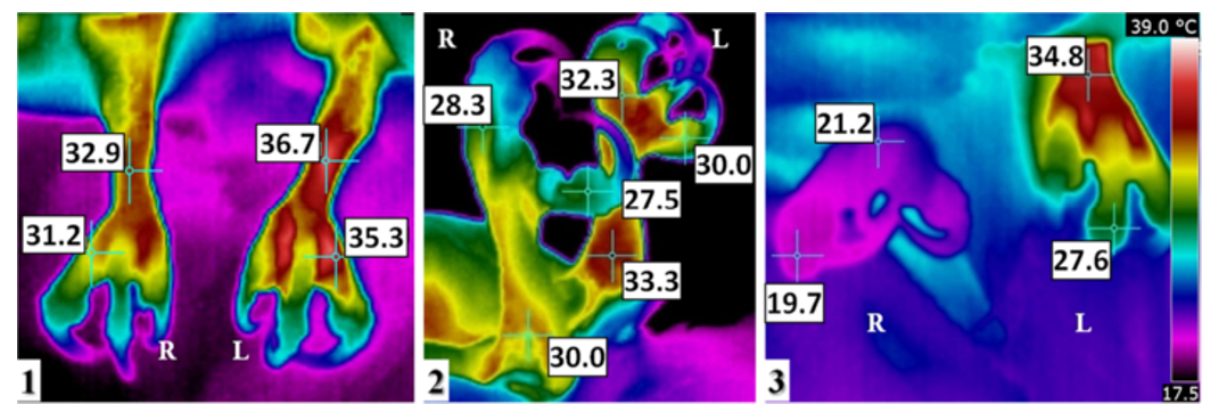

Figure 3 Thermal analysis of the osprey (P. haliaetus). Case 3. Thermal images of legs. (1) Dorsal view and (2) right lateral view of the legs during the first examination. (3) Dorsal view on the day that euthanasia was practiced. Initial designated right (R) and left (L) legs. A physiological thermal pattern is observed in the left leg. The thermal range is the same for Figure 3(1-3). 
[28-30]. Tissue is damaged due to the direct effects of the electrical current as it dissipates through organs $[29,30]$. Moreover, as this injured animal was located close to power lines, electrocution was highly suggestive.

The anamnesis, the veterinary examinations, and the histopathological analyses and necropsies, when performed, confirmed electrocution of these three animals. Thermographically, temperature reduction caused by electrocution was detected since the animals' admission, and prior to macroscopic lesions appearing. Additionally, the comparison made of the thermographs before and after physiotherapy revealed that thermography may help predict tissue damage prognosis and guide rehabilitation efforts.

Thermographically, injured tissues were cooler than the corresponding healthy ones and the thermal pattern was altered, which showed that thermal symmetry and thermal distribution are more important parameters than absolute temperature. Mabuchi et al. [11] drew the same conclusion when assessing the application of thermography for clinical diagnoses in humans. However, as reference absolute values are currently lacking, each clinical case should be studied carefully by performing thermography before and during rehabilitation in order to follow the thermal evolution. Although thermography is the most rapid and non-invasive tool for electrocution diagnosis, histopathology should be used to confirm the suspicious cases.

\section{Conclusions}

Thermography is a rapid, stress-free and objective tool that allows: the early detection of asymmetry temperature distribution and lesions consistent with electrocution without necropsy or amputation; the determination of areas damaged by the entry and exit of an electric current; the assessment of the animal's clinical status; the diagnosis of pathologies associated with electrocution, such as fractures and patagium retraction; and the evaluation of how lesions evolve with different treatments; all of which can contribute to more effective treatment.

\section{Competing interests}

The authors declare that they have no competing interests.

\section{Authors' contributions}

MM contributed by taking the thermograms and images analysis and by writing the manuscript. FG, ON, IL, MAJ and SJS helped draft the manuscript. $\mathrm{FG}, \mathrm{ON}$ and IL contributed with the clinical diagnosis, treatments and assessments. MAJ contributed by performing the histopathology analysis. SJS contributed with the physiotherapy diagnosis and treatment at GREFA. JMSV contributed to coordinating and reviewing the whole process. All the authors have read and approved the final manuscript.

\section{Acknowledgements}

The authors acknowledge the staff and volunteers of the GREFA and Vallcalent rehabilitation centres for their assistance and devotion. We acknowledge the Kirma physiotherapy centre for their collaboration in the treatment of the Lammergeier. Mar Melero is the recipient of a PhD student grant from the Complutense University of Madrid.

\section{Author details}

${ }^{1}$ VISAVET Centre and Animal Health Department, Veterinary School, Complutense University of Madrid, 28040 Madrid, Spain. ${ }^{2}$ GREFA Native Fauna and Their Habitat Rehabilitation Group, 28220 Majadahonda, Spain. ${ }^{3}$ Wildlife Rehabilitation Centre of Vallcalent, 25003 Lleida, Spain. ${ }^{4}$ Medicine and Surgery Department (Anatomic Pathology), Veterinary School, Complutense University of Madrid, 28040 Madrid, Spain.

Received: 24 September 2012 Accepted: 17 July 2013

Published: 23 July 2013

\section{References}

1. Molina-López RA, Casal J, Darwich L: Causes of morbidity in wild raptor populations admitted at a wildlife rehabilitation centre in Spain from 1995-2007: a long term retrospective study. PLoS One 2011, 6(9):e24603.

2. Burfield IJ: The conservation status and trends of raptors and owls in Europe. Ambio 2008, 37(6):401-407.

3. González LM, Margalida A, Mañosa S, Sánchez R, Oria J, Molina Jl, Caldera J, Aranda A, Prada L: Causes and spatio-temporal variations of non-natural mortality in the vulnerable Spanish imperial eagle Aquila adalberti during a recovery period. Oryx 2007, 41(4):495-502.

4. Guil F, Fernández-Olalla M, Moreno-Opo R, Mosqueda I, Gómez ME, Aranda A, Arredondo A, Guzmán J, Oria J, González LM, Margalida A: Minimising mortality in endangered raptors due to power lines: the importance of spatial aggregation to optimize the application of mitigation measures. PLoS One 2011, 6(11):e28212.

5. Bevanger K: Biological and conservation aspects of bird mortality caused by electricity power lines: a review. Biol Conserv 1998, 86(1):67-76.

6. Janss GFE, Ferrer M: Avian electrocution on power poles: European experiences. In In Birds and power lines: collision, electrocution and breeding. Edited by Ferrer M, Janss GFE. Madrid: Quercus; 1999:145-164.

7. Lehman RN, Kennedy PL, Savidge JA: The state of the art in raptor electrocution research: a global review. Biol Conserv 2007, 136(2):159-174.

8. Routh A, Sanderson S: Waterfowl. In In Handbook of Avian Medicine. 2nd edition. Edited by Tully TN, Dorrestein GM, Jones AK. Oxford: Butterworth-Heinemann; 2009:234--265.

9. Üzün I, Akyildiz E, İnanici MA: Histopathological differentiation of skin lesions caused by electrocution, flame burns and abrasion. Forensic Sci Int 2008, 178(2-3):157-161.

10. Mc Cafferty DJ: The value of infrared thermography for research on mammals: previous applications and future directions. Mamm Rev 2007, 37(3):177-255.

11. Mabuchi K, Chinzei T, Fujimasa I, Haeno S, Motomura K, Abe Y, Yonezawa T: Evaluating asymmetrical thermal distributions through image processing. IEEE Eng Med Biol Maq 1998, 17(4):47-55.

12. Renkielska A, Nowakowski A, Kaczmarek M, Dobke MK, Grudzinski J, Karmolinski A, Stojek W: Static thermography revisited - an adjunct method for determining the depth of the burn injury. Burns 2005, 31(6):768-775.

13. Tepper M, Neeman R, Milstein $Y$, David MB, Gannot I: Thermal imaging method for estimating oxygen saturation. J Biomed Opt 2009, 14(5):054048.

14. Dirección General para la Biodiversidad. Ministerio de Medio Ambiente: Catálogo Nacional de Especies Amenazadas. Madrid: Listado de taxones por categorías de amenazas. R.D. 439/1990, R.D. 139/2011; 2011.

15. IUCN 2012. IUCN Red List of Threatened Species. www.iucnredlist.org.

16. Morgan PB, Soh MP, Efron N: Potential applications of ocular thermography. Optom Vis Sci 1993, 70(7):568-576.

17. Colegrave N, Engel J, Plowman AB: Randomisation tests. In In Zoo research guidelines: Statistics for typical zoo datasets. Edited by Plowman AB. London: BIAZA; 2006:7-16.

18. Orosz SE, Ensley PK, Haynes CJ: Avian surgical anatomy: thoracic and pelvic limbs. Philadelphia: W.B. Saunders; 1992.

19. Jato S, Otero I, González F, López I, Mendoza JL: Patagium rehabilitation treatment in wild birds following long-term wing immobilization. Wild Rehabilitation Bull 2011, 29(2):33-41.

20. Gross TL, Ihrke PJ, Walder EJ, Affolter VK: Necrotizing diseases of the epidermis. In Skin Diseases of the Dog and Cat, Clinical and Histopathologic Diagnosis. 2nd edition. Ames: Blackwell Science; 2005:94-97. 
21. Thomsen HK, Danielsen L, Nielsen O, Aalund O, Nielsen KG, Karlsmark T, Genefke IK: Early epidermal changes in heat- and electrically injured pig skin. I. A light microscopic study. Forensic Sci Int 1981, 17(2):133-143.

22. Danielsen L, Gniadecka M, Thomsen HK, Pedersen F, Strange S, Nielsen KG, Petersen HD: Skin changes following defibrillation. The effect of high voltage direct current. Forensic Sci Int 2003, 134(2-3):134-141.

23. Myers DA: Common procedures and concerns with wildlife. Vet Clin North Am Exot Anim Pract 2006, 9(2):437-460.

24. Baer CK: Guidelines for euthanasia of nondomestic animals. Lawrence: American Association of Zoo Veterinarians (AAZV); 2006.

25. American Veterinary Medical Association: AVMA Guidelines on Euthanasia. In Formerly report of the AVMA panel on euthanasia. Schaumburg: AVMA; 2007.

26. Schmidt RE, Reavill DR: A practitioner's guide to avian necropsy. Necropsy CD, Zoological Education Network; 2003. ISBN ISBN: 0-9706395-0-3.

27. Rae MA: Practical avian necropsy. Semin Avian Exot Pet Med 2003, 12(2):62-70.

28. Koumbourlis AC: Electrical injuries. Crit Care Med 2002, 30(11 Suppl):424-430.

29. Ritenour AE, Morton MJ, MCManus JG, Barillo DJ, Cancio LC: Lightning injury: a review. Burns 2008, 34(5):585-594.

30. Fish RM, Geddes LA: Conduction of electrical current to and through the human body: a review. Eplasty 2009, 9:e44.

doi:10.1186/1746-6148-9-149

Cite this article as: Melero et al:: Detection and assessment of

electrocution in endangered raptors by infrared thermography. $B M C$

Veterinary Research 2013 9:149.

\section{Submit your next manuscript to BioMed Central and take full advantage of:}

- Convenient online submission

- Thorough peer review

- No space constraints or color figure charges

- Immediate publication on acceptance

- Inclusion in PubMed, CAS, Scopus and Google Scholar

- Research which is freely available for redistribution 